\title{
Tosferina: una mirada epidemiológica, clínica y del laboratorio
}

\author{
Pertussis: an epidemiological, clinical and laboratory view
}

\author{
Andrés F. Rúa-Correa $M D^{1}$, Javier L. Arias-Bolívar $M D^{1}$, \\ Paula A. Orozco-Yepes $M D^{1}$, Jeison Pinto-Mejía $M D^{2}$, \\ Isaura P. Sánchez $P h D^{3}$
}

Resumen: la tosferina es una enfermedad aguda bacteriana, causada por Bordetella pertussis, que afecta el tracto respiratorio superior, produciendo fuertes accesos de tos, asfixia y cianosis. Otros microorganismos pueden producir un cuadro similar a la tosferina, conocido como síndrome coqueluchoide, el cual es su principal diagnóstico diferencial. La enfermedad se presenta en su mayoría en lactantes menores, especialmente los que no están adecuadamente inmunizados y están en contacto con adolescentes y adultos, potenciales reservorios de la enfermedad. Actualmente se realiza el diagnóstico mediante criterios clínicos y microbiológicos, que permiten clasificar al paciente en caso probable o confirmado. En cuanto al tratamiento el manejo estándar de la enfermedad incluye antibióticos tipo macrólidos. Dependiendo de la severidad del cuadro se implementa tratamiento de soporte con oxígeno, corticoides, vasodilatadores pulmonares y sedantes. La mejor forma de prevención es una alta cobertura de vacunación cumpliendo los esquemas propuestos. La protección inducida por la vacuna alcanza entre $70 \%-85 \%$ de los títulos de anticuerpos, los cuales disminuyen entre

\footnotetext{
${ }^{1}$ Estudiantes de medicina, Facultad de Ciencias de la Salud, Programa de Medicina, Corporación Universitaria Remington. Medellín, Colombia.

2 Médico. Docente, Facultad de Ciencias de la Salud, Programa de Medicina, Corporación Universitaria Remington. Medellín, Colombia

${ }^{3}$ Bióloga, PhD en Biología. Docente-Investigador, Grupo de Investigaciones Biomédicas UniRemington, Facultad de Ciencias de la Salud, Programa de Medicina, Corporación Universitaria Remington. Medellín Colombia. Correspondencia: Calle 51 \#51-27. Correo electrónico: i isaura.sanchez@uniremington.edu.

Conflicto de intereses: los autores declaran que no tienen conflicto de intereses Medicina \& Laboratorio 2016; 22: 211-238

Módulo 1 (La clínica y el laboratorio), número 116. Editora Médica Colombiana S.A. $2016^{\circ}$

Recibido el 09 de junio de 2016; aceptado el 28 de junio de 2016
} 
los 4-7 años posvacunación, lo que hace imprescindible la implementación de una dosis de refuerzo a los 18 meses y 5 años. En Colombia todavía falta el establecimiento de otras opciones a edades más avanzadas, previniendo que la persona joven y adulta sea el reservorio de la enfermedad. En general, los hallazgos y avances en el estudio de la tosferina evidencian que es una entidad clínica con un aumento significativo en su incidencia en la población pediátrica, a pesar de que se cree que está totalmente controlada.

Palabras claves: tosferina, terapia, vacuna antipertussis, tos, Bordetella pertussis.

Abstract: Pertussis is an acute bacterial disease caused by Bordetella pertussis that affects the upper respiratory tract, producing severe cough, asphyxia, and cyanosis. Other microorganisms can cause a similar clinical picture to pertussis, known as coqueluchoide syndrome, which is the main differential diagnosis. The disease occurs mainly in infants, especially those who are not adequately immunized and are exposed to adolescents and adults, the potential reservoirs of the disease. Currently the diagnosis is by clinical and microbiological criteria for classifying the patient as probable or confirmed case. The treatment standard management is with antibiotic, especially macrolides. Depending on the severity of case, support treatment including oxygen, steroids, sedatives, and pulmonary vasodilators is implemented. The best prevention of disease is high vaccination coverage, fulfilling with the schemes proposed. The induced protection by the vaccine reaches between $70 \%-85 \%$ of antibody titers, which decrease between 4-7 years post vaccination, which make essential to implement a strategy of booster shot at 18 months and 5 years-old. However, Colombia has not developed other options at older ages, that prevent the young and adults become the reservoir of the disease. Overall findings and advances in the whooping cough study shows that is a clinical entity with a significant increase of its incidence in the pediatric population, although it is believed that is fully controlled.

Key words: Pertussis, therapy, Pertussis vaccine, cough, Bordetella pertussis.

Rúa-Correa AF, Arias-Bolívar JL, Orozco-Yepes PA, Pinto-Mejía J, Sánchez IP. Tosferina: una mirada epidemiológica, clínica y del laboratorio. Medicina \& Laboratorio 2016; 22: 211-238.

\section{L}

a tosferina es una enfermedad aguda bacteriana del aparato respiratorio que afecta a toda la población en general, especialmente a los niños menores de un año de edad, en quienes ocurren la mayoría de las complicaciones. En las últimas décadas se ha venido presentando un aumento en su incidencia hasta alcanzar un resurgimiento no despreciable de la enfermedad, por lo que se considera un problema de salud pública y una enfermedad endémica actual, de distribución mundial y caracterizada por picos epidémicos cada tres a cuatro años $[1,2]$. 
En el resurgimiento de la tosferina influyen varios factores que incluyen el subdiagnóstico de la enfermedad, dado que no siempre se presenta en sus fases características, el uso de vacunas poco eficaces, la mala cobertura, la evolución de la patogenia de la bacteria, la aparición de la enfermedad en los adolescentes y adultos (principales reservorios), la inmunidad adquirida en la vacunación antigua, ya que se ha visto el descenso de la inmunidad en un plazo de cinco años, y el poco conocimiento del personal médico que lleva a tratar empíricamente a los pacientes por simple sospecha [1].

Todos estos factores contribuyen a que la tosferina tenga un abordaje inadecuado que favorece el progreso a un síndrome coqueluche grave, que a pesar der ser una condición patológica de prevalencia baja es mortal y de mayor presentación en menores de seis meses de edad. Los desencadenantes hacia una evolución fatal y su fisiopatología no están aún claros; lo importante es tener la perspicacia clínica para sospechar una hipertensión pulmonar, ya que las complicaciones tienen una evolución rápida que lleva a la pronta muerte del paciente [2,3].

La mejor forma de tratar esta enfermedad es mediante su prevención utilizando los métodos de vacunación; no obstante, en la actualidad no se cuenta con una vacuna que brinde protección duradera. Para esto, la principal manera de abordaje es empezar a implementar refuerzos de la vacuna (DPTa) con base en la epidemiologia de la enfermedad y los grupos poblacionales en los que se presenta mayor prevalencia [3-5].

En este contexto, la información epidemiológica del Sistema Nacional de Vigilancia en Salud Pública (SIVIGILA) para el 2013 en Colombia, reportada en la Guía de Práctica Clínica para la Identificación y Manejo de la Tosferina, mostró que de $2.988(22,5 \%)$ casos confirmados $472(15,8 \%)$ fueron menores de un mes, 1.435 (48\%) menores de un año, 808 (27\%) niños entre uno y cuatro años de edad y $459(15,4 \%)$ adolescentes mayores de 14 años y adultos, de los cuales el $44,5 \%$ y el $7,1 \%$ requirieron hospitalización o presentaron una complicación (neumonía principalmente), respectivamente [6].

La proyección general es que los países en los que todavía no se tiene un adecuado esquema de refuerzos de vacunación sobre la población juvenil y adulta, como se ha venido realizando en países como Estados Unidos y Suecia, instauren políticas de acción que estén dirigidas hacia la prevención de estas patologías para evitar llegar a las complicaciones mortales como el síndrome coqueluche grave [4]. El objetivo del presente trabajo es realizar una descripción clínica y epidemiológica de las actualizaciones sobre la tosferina en pediatría, respaldada por la literatura médica y científica, haciendo un énfasis detallado en la descripción de nuevas opciones y de las investigaciones que se están implementando en diferentes países del mundo. 


\section{Definición de la tosferina}

La tosferina o coqueluche es una enfermedad infectocontagiosa prevenible, causada por la bacteria Bordetella pertussis y, en menor frecuencia, por Bordetella parapertussis. Estas bacterias entran al sistema respiratorio por medio de microgotitas expulsadas por los accesos de tos y, al llegar al sitio, se adhieren a los cilios, especialmente del sistema respiratorio superior. Las bacterias liberan toxinas que dañan los cilios y causan inflamación, produciendo los síntomas respiratorios como estridor y accesos de tos prolongados que puede llevar a períodos de apnea $[4,5]$.

De acuerdo a los criterios de definición de la enfermedad del Ministerio de Salud y Protección Social de Colombia se estableció la siguiente clasificación, que agrupa a los pacientes según el rango de edad para su abordaje clínico $[4,6,7]$ :

- Menor de tres meses: toda infección respiratoria aguda, acompañada al menos de uno de los siguientes síntomas o signos: tos en accesos, estridor, apnea, cianosis o vómito después de toser.

- De tres meses a 12 años: toda infección respiratoria con tos de más de una semana de duración, acompañada de uno o más de los siguientes síntomas o signos: tos paroxística, estridor o vómito después de la tos sin otra causa aparente, o niños con tos paroxística intensa acompañada de estridor de cualquier tiempo de evolución.

- Mayores de 12 años: Toda infección respiratoria acompañada de tos prolongada de más de dos semanas de duración y presencia o no de paroxismos, expectoración y vómito.

\section{Epidemiología}

La tosferina, a pesar de ser una enfermedad que ha disminuido notablemente, tiene un historial de morbilidad y mortalidad supremamente importante. Durante la era prevacunal se consideraba la primera causa de muerte por enfermedades infectocontagiosas. En el siglo pasado constituía una de las enfermedades respiratorias con mayor frecuencia, sobre todo en la población pediátrica menores de un año de edad $[8,9]$. Sin embargo, durante los últimos cincuenta años el también llamado coqueluche se mantuvo relativamente controlado gracias a la implementación de la vacuna combinada con tétano y difteria (DPT).

Según lo publicado por los Centros para el Control y la Prevención de Enfermedades (CDC), la vacuna se comenzó a distribuir en Estados Unidos en 1940; momento hasta el cual la tosferina tenía una morbilidad por año de 150.000 a 260.000 casos y una mortalidad anual de hasta 9.000 casos, y a partir del que 
se produjo una reducción de la mortalidad hasta del 70\%. A pesar de esto se continuaban presentando tasas muy altas de infección por la falta de promoción y cobertura y los elevados índices de complicaciones debido a la enfermedad no prevenida adecuadamente mediante vacunación, lo que originó una preocupación de la población en cuanto a la seguridad de la vacuna y llevó a una reducción de la inmunidad contra la tosferina en países como el Reino Unido [10].

Como consecuencia, a mediados de los setenta, en el Reino Unido, se presentó una epidemia con más de 100.000 casos reportados y 36 muertes debido a la tosferina. Esto condujo también a repercusiones en países como Japón, donde se presentó una epidemia por una disminución en la vacunación contra la tosferina que pasó del $80 \%$ en 1974 a un $20 \%$ en 1979 , lo que en consecuencia produjo más de 13.000 casos y 41 muertes en ese mismo año. Debido a estos hechos, en 1991 se iniciaron nuevos estudios y se desarrolló, en Estados Unidos, la vacuna acelular de la Difteria, Tétano y Tosferina (DPTa), la cual era más efectiva y presentaba menos reacciones adversas $[11,12]$. No obstante, a pesar de la integración de esta nueva vacuna existe un resurgimiento no despreciable de la enfermedad en la actualidad.

Hoy en día la tosferina se considera un problema de salud pública, aun en los países desarrollados que cuentan con altos estándares de cobertura en vacunación [13]. Se calcula que cada año se presentan alrededor de cincuenta millones de casos de tosferina a nivel mundial y más de 600.000 muertes anualmente [5]. En 2000, la tosferina representó el $17 \%$ de todas las muertes prevenibles con la aplicación de vacunas en menores de 15 años, con una tasa de letalidad de aproximadamente el $0,1 \%$ [14].

De acuerdo con el informe de 2008, suministrado por la Organización Mundial de la Salud (OMS), en 2004 se presentaron 254.000 muertes por tosferina, correspondientes al 0,4\% del total mundial de muertes, casi todas en menores de 15 años; el $86 \%$ presentadas en África y el sureste de Asia y menos del $2 \%$ en los países en vía de desarrollo de América. Así mismo, al medir la carga de la enfermedad en años de vida ajustados por discapacidad (AVAD) perdidos, la tosferina produjo un total de 9.882.000 AVAD perdidos en el 2004 [14]. Los países subdesarrollados son los que tienen más probabilidades de sufrir la enfermedad, relacionada con los bajos ingresos y las mayores posibilidades de que la enfermedad tenga una alta presencia [12].

Así mismo, la OMS divulgó que en 2008 se presentó un pico de dieciséis millones de casos nuevos de tosferina a nivel mundial y afirmó que habrán más picos y con mayor gravedad en el futuro [15]. Se cree que existen diferentes causas que pueden explicar este fenómeno de aumento de la prevalencia tales como la cobertura inadecuada, el uso de vacunas poco eficaces o con compuestos distintos distribuidas de manera ilícita, la evolución en la patogenia de la bacteria y la en- 
fermedad en los adolescentes y adultos, en los que puede disminuir la inmunidad tras la vacunación antigua, partiendo que se ha comprobado el descenso de la efectividad de la vacuna luego de 5 años de su aplicación $[1,6,16]$.

De acuerdo con la información suministrada a través del SIVIGILA, en el año 2013 se notificaron en Colombia 13.278 casos de tosferina. De estos, $27(0,2 \%)$ fueron clasificados como probables (caso que cumple con los criterios de diagnóstico clínico, pero que no ha sido demostrado microbiológicamente ni se ha filiado epidemiológicamente a un caso definitivo) y 2.988 casos $(22,5 \%)$ como confirmados (cualquier cuadro respiratorio con cultivo positivo para Bordetella pertussis o cualquier cuadro que cumpla con los criterios de diagnóstico clínico, con PCR positiva para Bordetella pertussis o asociación epidemiológica a un caso con diagnóstico microbiológico). De estos últimos, 1.696 fueron comprobados por el laboratorio, 958 por la clínica y 334 por criterio epidemiológico. Por su parte, 10.263 (77,3\%) casos fueron descartados.

La incidencia de tosferina en la población general colombiana durante 2013 fue de 6,3 casos por 100.000 habitantes, y llegó a ser de 52,1 casos por 100.000 en los niños menores de 4 años [6]. Sin embargo, estas cifras podrían estar subvaloradas, debido a que hay reportes incompletos que no permiten predecir el verdadero impacto de la enfermedad [5]. Este mismo año se reportaron 28 muertes confirmadas por tosferina en Colombia, todas ellas en menores de un año; sin embargo, se estima un mayor número de muertes debido a que también se encuentran informes incompletos de la mortalidad y diagnósticos erróneos $[6,17]$.

Por otra parte, un estudio prospectivo realizado en Brasil entre 2010 y 2011 [18] permitió concluir que uno de cada 20 pacientes adolescentes y adultos con tos prolongada tiene tosferina. La edad media de los 192 individuos con una tos persistente por más de 14 días, identificados como casos sospechosos, fue de 40,7 años, en los cuales la dosis final de la vacuna contra la tosferina se debió aplicar al menos 8 años atrás. Por su parte, 10 casos fueron confirmados, obteniendo una prevalencia estimada del 5,21\%. Estos hallazgos sugieren que un gran porcentaje de personas que presentan tos crónica podría estar cursando con tosferina, afectando principalmente a los menores de un año que son expuestos en el hogar, en quienes la enfermedad tiene una sintomatología y desenlace mucho más grave. Un buen abordaje del prestador de servicio de salud puede prevenir que se aumenten los casos de tosferina ante un manejo conjunto de la familia, si presentan sintomatología respiratoria.

La tosferina es una de las infecciones más contagiosas que existe por lo que la tasa de ataque en una población susceptible, en caso de exposición, es cercana al $100 \%$. Esta enfermedad afecta a toda la población en general teniendo como principal hospedero los jóvenes y los adultos, quienes transmiten la enfermedad a los lactantes menores, los recién nacidos o los niños que son susceptibles por in- 
adecuada inmunización [13]. El principal medio de prevención es la inmunización a través de la vacuna triple (DPT; difteria, tétanos y tosferina); no obstante, ni la enfermedad natural ni la vacunación dan inmunidad por toda la vida.

En la actualidad la tosferina se reconoce como una enfermedad endémica a nivel mundial, caracterizada por ciclos epidémicos cada tres o cuatro años [6,7,19-22]. Así mismo, se considera una enfermedad de difícil diagnóstico porque no siempre se presenta en sus fases características, lo que hace que haya un mayor índice de morbimortalidad y una subestimación de la enfermedad.

\section{Etiología}

La tosferina es causada por bacterias pequeñas Gram negativas del género Bordetella, tipo de organismo protobacteriano. Las especies de Bordetella son cocobacilos encapsulados, pleomorfos, inmóviles, no esporulados (véase figura 1), caracterizados por su difícil cultivo y ser aerobios obligados, excepto Bordetella petrii. Estas bacterias son consideradas parasitarias debido a que sobreviven muy poco tiempo en un medio externo [23].

La etiología de la tosferina no es tan variada como parece, las especies de importancia que producen patogenia en los humanos son específicamente tres y se

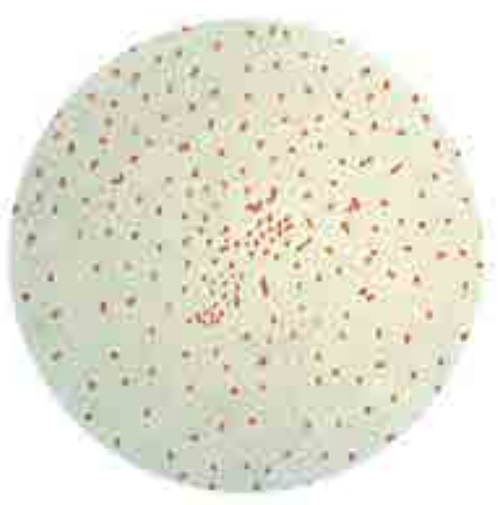

Figura 1. Coloración de Gram de la bacteria Bordetella pertussis. Tomada de la Biblioteca de Imágenes de Salud Pública (PHIL; del inglés, $P u$ blic Health Image Library) de los Centros para el Control y Prevención de Enfermedades (CDC), con número de identificación \# 2121, 1979. pueden dividir en microorganismos que producen la enfermedad epidémica o esporádica [23]. Los principales agentes implicados son: a) Bordetella pertussis, la cual es la única causante de tosferina epidémica, pero también ocasionalmente produce la forma esporádica, b) Bordetella parapertussis, que causa tosferina esporádica, y c) Bordetella bronchiseptica, que aunque sea más habitual en animales como roedores, perros o cerdos, se han evidenciado casos esporádicos de infección en los seres humanos, sobre todo en inmunocomprometidos o en niños con exposición constante a los animales [7,16,24].

\section{Etiopatogenia}

La infección por Bordetella spp. comienza con su adhesión a las células epiteliales ciliadas del aparato respiratorio superior, luego de ingresar por medio de la inhalación de microgotitas que contienen las bacterias, provenientes principalmente de adultos infectados que las transmiten a los niños pequeños y lactantes. Una vez 
en el aparato respiratorio se comienzan a multiplicar y a liberar ciertas toxinas, que son muy importantes para su patogenicidad, produciendo un daño tisular localizado [25].

Bordetella pertussis, el principal agente, genera diversos factores de virulencia, entre ellos las exotoxinas que son las que producen las manifestaciones clínicas y la respuesta inmunológica marcada. Entre las principales toxinas se encuentran $[26,27]$ :

- Toxina pertussis (TP), pertusinógeno o factor promotor de linfocitos: solo Bordetella. pertussis expresa esta toxina, la cual está conformada por cinco subunidades (S1-S5). Esta es la toxina más virulenta, responsable de la linfocitosis que se presenta en la tosferina, la cual está dada por la unión de la proteína a los linfocitos circulantes, lo que impide su regreso a los órganos linfoides y favorece su acumulación en la circulación.

- Citotoxina traqueal (CTT): cuando se encuentra en niveles bajos produce la parálisis ciliar y en niveles altos destrucción de las células ciliadas; no obstante, no tiene valor en la enfermedad humana.

- Toxina termolábil, toxina dermonecrótica (TD), factor letal o lienotoxina: es la responsable de la necrosis y de la destrucción tisular localizada de las capas profundas del epitelio respiratorio; además de que también produce parálisis ciliar.

- Hemaglutinina filamentosa (HAF): encargada de la unión de las fimbrias de los microorganismos al epitelio respiratorio, produce una elevación de la respuesta inmunológica.

- Toxina extracelular o toxina adenilato ciclasa: es la encargada de la protección de la bacteria, lesionando la célula inmune efectora. También inhibe la quimiotaxis, la fagocitosis y la destrucción mediada por leucocitos.

\section{Manifestaciones clínicas}

La tosferina cursa con tres fases clínicas que incluyen: la catarral, la paroxística, que es la más fácilmente transmisible, y de convalecencia (véase figura 2) [4]. Esta enfermedad tiene un período de incubación de cinco a 21 días, con un promedio de siete días. Primero se encuentra la fase catarral, similar a un resfriado común que puede durar de una a dos semanas; la tos es discreta, en ocasiones puede o no presentar fiebre de poca intensidad y en los lactantes menores episodios de apnea [17]. Esta fase es muy fácil de que pase desapercibida por sus síntomas inespecíficos, por lo que no se sospecha y menos se diagnostica, sino hasta la próxima fase que es mucho más llamativa $[7,28]$.

El paso de la fase catarral a la fase paroxística se considera crítica y de vital importancia pues es el período en el que los pacientes tienen una mayor capacidad de 
contagio [29] y es la más característica de la enfermedad. Este estado se prolonga más o menos 30 días, en los cuales la tos es severa y se presenta en accesos de entre cinco a 20 o más episodios continuos sin un intervalo de inspiración, lo que conduce a apnea y produce en el ciclo respiratorio un estridor o ruido específico de la enfermedad, que es desencadenado por la fuerza con que se producen los ataque de tos. La hipoxia que se genera se puede manifestar con cianosis y a veces con convulsiones. Como característica propia de la enfermedad al final de los paroxismos de tos se produce un episodio de vómito. En ocasiones el acceso se repite varias veces hasta lograr desprender el tapón de moco que obstruye las vías aéreas [19].

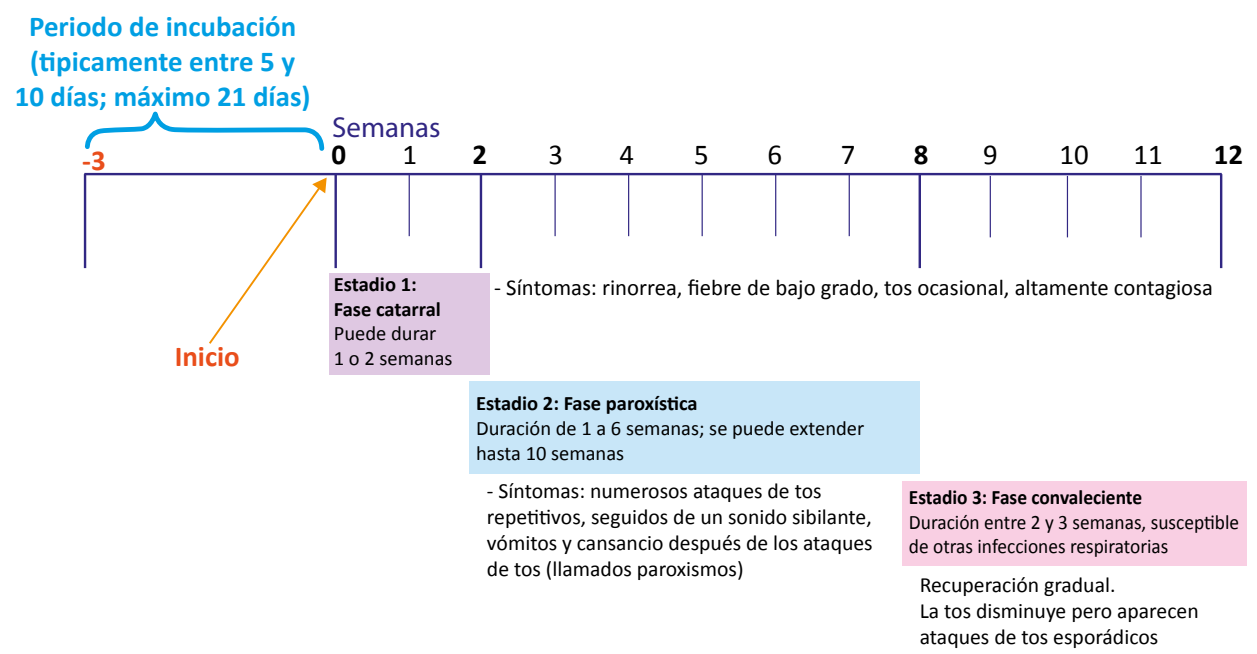

Figura 2. Fases clínicas de la tosferina. Tomada y modificada de "Pertussis (Whooping Cough): Signs and Symptoms" por los Centros para el Control y Prevención de Enfermedades (CDC) en: http://www.cdc. gov/pertussis/about/signs-symptoms.html

El paciente queda exhausto pero rápidamente recobra la apariencia de una persona sana hasta el siguiente paroxismo. De manera importante, la media de tiempo de la presentación de la tos es de aproximadamente 47 días, el doble o incluso el triple de la media de otra infecciones respiratorias en lactantes, aunque se aspira que hayan casos con intervalos de tiempo mayores [23]. Por ejemplo, en China se le acuña el nombre de la enfermedad de los 100 días debido a la duración de la tos. En pocas palabras la fase paroxística se puede decir que presenta la triada [30]:

- Paroxismos o accesos de tos rápida

- Estridor seguido de la tos, de carácter inspiratorio

- Emesis posterior a los episodios de tos 
Posteriormente, aproximadamente en los 15 días siguientes, viene el período de convalecencia, donde los episodios de crisis se hacen cada vez más separados y con una menor intensidad. Esta forma de tosferina es insidiosa y corresponde a la del lactante mayor, niños y adultos que no han sido inmunizados [19]. En los niños más pequeños no se presenta el estridor inspiratorio, aunque es más frecuente el estado cianótico, los períodos de apnea, las convulsiones y la bradicardia posterior a la tos, que puede no ser intensa, pasar desapercibida o incluso no presentarse [20].

Entretanto, en los lactantes menores de tres meses la presentación de tosferina es cada vez más inespecífica, pero son más propensos a tener un cuadro clínico más grave e incluso mortal conocido como "tosferina maligna", que se caracteriza por ser un proceso fulminante de tos paroxística, pausas de apnea y fallo respiratorio progresivo con bronconeumonías, atelectasias e hiperleucocitosis extrema. Esto conduce a hipertensión pulmonar e hipoxemia rápidamente progresivas, lo cual lleva a un estado acidótico. Además, esta condición puede ser refractaria al tratamiento convencional $y$, en el peor de los casos, ocasiona shock y muerte hasta en un $75 \%$, principalmente en los niños no inmunizados $[21,22,31]$.

En los menores de un año las infecciones por Bordetella pertussis se pueden presentar sin las características típicas con las que clásicamente se describe la enfermedad (tos paroxística, emetizante, con estridor inspiratorio), sino bajo la forma de apneas, distrés respiratorio inespecífico o bradicardia. Además, son varios los microorganismos que se pueden presentar con manifestaciones clínicas similares. En los adultos y los adolescentes también se manifiesta de forma atípica con una tos prolongada, persistente y no específica [23]. Algunos reportes han establecido que la edad más joven, los menores de dos meses y la leucocitosis severa (recuento de glóbulos blancos $>100.000 / \mathrm{mm}^{3}$ ) son predictores de mal pronóstico de la enfermedad [20].

\section{Complicaciones}

La principal causa de muerte en los pacientes infectados por Bordetella pertussis es la neumonía, siendo los menores de edad los más afectados y, en forma más crítica, aquellos en los primeros 12 meses de vida [19]. Otras complicaciones incluyen las neurológicas, como las convulsiones (2\%) y la encefalopatía $(0,5 \%)$, las nutricionales por deshidratación, emesis repetitiva y pérdida del apetito, las que son debidas a los efectos de la presión durante los accesos de tos, como el neumotórax, las atelectasias, las fracturas costales, las hernias y el prolapso rectal, y los sangrados como hematomas subdurales, hemorragias gastrointestinales, hemorragias subconjuntivales, epistaxis y petequias $[5,19,21,32]$.

Las principales complicaciones del síndrome de coqueluche son las infecciones, en especial las respiratorias como la bronconeumonía, la bronquitis, la bronquiolitis, la neumonitis, las apneas, el empiema pleural y atelectasias residuales, así 
como otitis media, debidas principalmente a la sobreinfección con microorganismos como Streptococcus pneumoniae, Haemophilus influenzae y Staphylococcus aureus [32]. La neumonía afebril del lactante es una importante enfermedad exclusiva de los niños en este período, que suele llegar a ser grave y es causada por microorganismos atípicos y resistentes a los tratamientos convencionales. Otra de las características de alto riesgo de esta enfermedad es su inicio asintomático, lo que aumenta el riesgo de morbimortalidad y la dificultad de su diagnóstico. Se han comprobado distintos casos de neumonía afebril del lactante relacionados con tosferina por lo que algunos llaman esta entidad como síndrome tosferinoso [33].

Las complicaciones en los adolescentes y los adultos son menos graves en comparación con los menores de un año, que es la población más crítica; sin embargo, en los mayores de edad que tengan alguna comorbilidad, como desnutrición, inmunodeficiencia y enfermedad renal crónica, tienen una sustancial elevación del índice de morbimortalidad [34].

Además de lo mencionado, se deben resaltar dos complicaciones que son la segunda causa de muerte después de las neumonías y tienen un alto riesgo de producir secuelas a largo plazo. Estas corresponden a la encefalopatía tosferínica o tosferinosa ( $1 / 100.000$ casos) y la llamada tosferina maligna o coqueluche maligno. La encefalopatía tosferínica es causada por la hipoxia generada por los paroxismos o directamente por las toxinas del microorganismo y lleva a convulsiones, alteración del estado de conciencia y secuelas neurológicas permanentes [25,30,35].

La tosferina maligna es una entidad grave que se da especialmente en menores de tres meses y se caracteriza por presentar una reacción leucemoide (mayor que 100.000 leucocitos $/ \mu \mathrm{L}$ ), con linfocitosis, paroxismos, períodos de apneas y fallo ventilatorio, que se acompaña de bronconeumonías, hipoxemia e hipertensión pulmonar, con daño miocárdico como afectación colateral, pudiendo llevar incluso a un estado de shock y una mortalidad del $75 \%[5,21,22,31]$.

\section{Diagnóstico}

Los criterios diagnósticos de la tosferina, de acuerdo a los CDC (Atlanta, Georgia, Estados Unidos) [27], incluyen:

- Diagnóstico clínico: caracterizado por una tos de duración mayor de dos semanas, más uno de los siguientes síntomas: tos paroxística, gallo inspiratorio o vómitos, tras los accesos de tos sin otra causa aparente.

- Diagnóstico microbiológico: aislamiento de Bordetella pertussis en una muestra de hisopado nasofaríngeo y reacción en cadena de la polimerasa (PCR; del inglés, Polymerase Chain Reaction) positiva. 
Con base en lo anterior los casos son clasificados como [19]:

- Caso probable: caso que cumple con los criterios de diagnóstico clínico, pero no se ha podido demostrar microbiológicamente ni se ha podido filiar epidemiológicamente a un caso definitivo.

- Caso confirmado: posibilidades: a) cualquier cuadro respiratorio con cultivo positivo para Bordetella pertussis, b) cualquier cuadro que cumple con los criterios de diagnóstico clínico, con PCR positiva para Bordetella pertussis o asociación epidemiológica a un caso con diagnóstico microbiológico.

El hemoleucograma se recomienda ordenarlo a los pacientes durante el estadio catarral e inicio del estadio paroxístico, ya que nos puede mostrar una leucocitosis de 15.000 o más leucocitos/ $\mu \mathrm{L}$, con más del $60 \%$ de linfocitos. Es frecuente especialmente en lactantes, no aparece en los parcialmente inmunizados y es mucho menos común en los adolescentes y adultos. En algunos casos hay verdaderas reacciones leucemoides [7].

\section{Diagnóstico clínico}

Alrededor del mundo el diagnóstico de la tosferina se establece por sospecha clínica, lo cual no es un método diagnóstico ideal, dado que la sintomatología de los pacientes puede variar en cada caso lo que lo hace poco preciso y específico [35]. Entre los principales criterios clínicos actuales para el diagnóstico de tosferina se encuentra la tos paroxística; no obstante, no es un buen predictor de la tosferina en los casos atípicos. En algunos pacientes la tosferina puede confundirse con una infección viral del tracto respiratorio que al no ser diagnosticada por medio de los elementos adecuados contribuye a la propagación de la enfermedad en la población general [24].

Un estudio realizado en niños para evaluar el impacto del diagnóstico molecular en la toma de las decisiones clínicas para el manejo de las infecciones respiratorias pediátricas demostró que cuando se hace el diagnóstico por el método de sospecha clínica uno de cada cinco casos (19\%) se pierde, concluyéndose que, ante la sospecha de tosferina, esta no puede ser diagnosticada únicamente por síntomas clínicos [36].

\section{Diagnóstico por laboratorio}

\section{Cultivo}

Los dos medios de cultivo más utilizados para el aislamiento de Bordetella pertussis son el medio de Bordet-Gengou (infusión de papa, glicerol y sangre de caballo/ carnero) y el agar Regan-Lowe o charcoal agar (suplementado con sangre de caballo al $10 \%$ y cefalexina $40 \mathrm{mg} / \mathrm{L}$ ). El cultivo requiere de una técnica adecuada para la obtención de la muestra nasofaríngea bien sea mediante el aspirado (lavado) o hisopado (exudado) de dacrón o alginato de calcio durante las dos primeras 
semanas de la fase catarral, cuando la bacteria está todavía en la región nasofaríngea (véase figura $\mathbf{3}$ ). Luego de ese período la sensibilidad disminuye a medida que progresa la fase de paroxismos; sin embargo, un cultivo negativo nunca excluye el diagnóstico de tosferina $[35,37]$.

El agar Regan-Lowe, en general, permite un mayor porcentaje de aislamientos, además de que el tiempo de estabilidad del medio es de cuatro a ocho semanas, a diferencia del medio Bordet-Gengou que es de tan sólo cinco días. Si bien en el agar Regan-Lowe

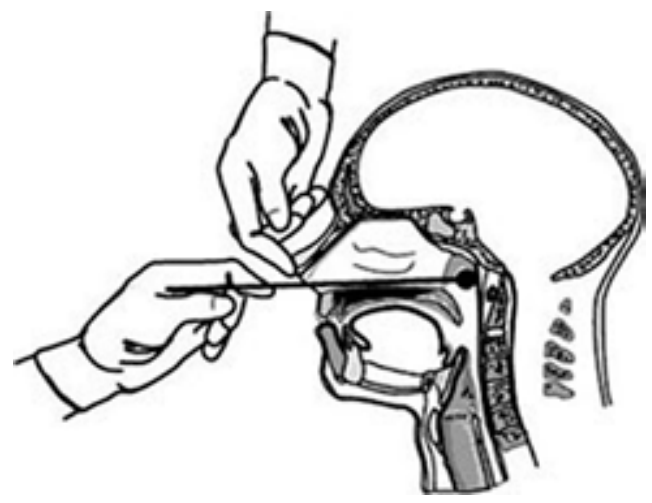

Figura 3. Técnica apropiada para la obtención de la muestra nasofaríngea por hisopado para el aislamiento de Bordetella Pertussis. Tomada de Manual for the surveillance of vaccine-preventable diseases, Chapter 10: Pertussis (p. 5) por Centers for Disease Control and Prevention, 2015, Atlanta, Giorgia, Estados Unidos. el crecimiento de Bordetella pertussis se puede observar después de tres a cinco días de incubación a $35^{\circ} \mathrm{C}-36^{\circ} \mathrm{C}$, se recomienda su incubación hasta 7 a 12 días para obtener resultados positivos (véase figura 4). Una vez obtenido el cultivo se requiere, además, la confirmación mediante métodos de aglutinación con antisueros específicos o por fluorescencia [35]. El medio de cultivo de Bordet-Gengou para el aislamiento de Bordetella pertussis se ha ido dejando a un lado por múltiples motivos, entre los cuales se encuentra la poca sensibilidad (menor que el $25 \%$ ) y el retraso de los resultados (siete a 10 días), entre otras razones [35].

A

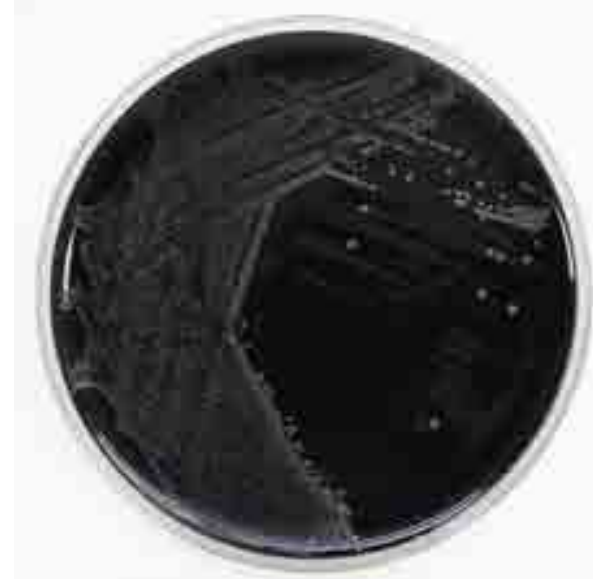

B

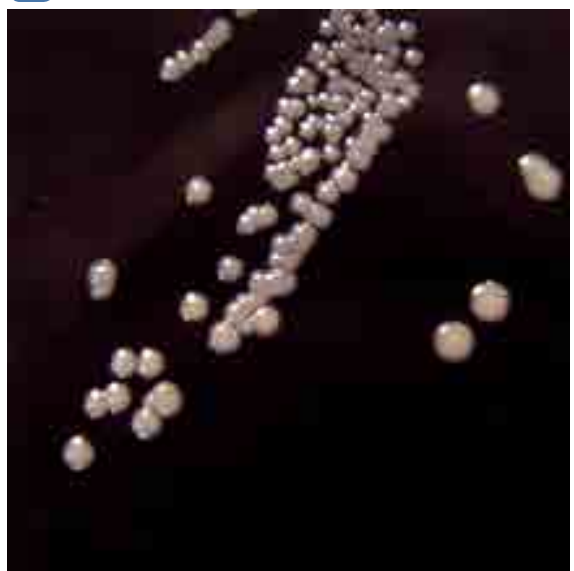

Figura 4. Bordetella pertussis en agar de Regan-Lowe. A. Se muestra el aislamiento a partir de un hisopado nasofaríngeo de un paciente con tosferina a los 7 días de crecimiento en $\mathrm{CO}_{2}$ al $10 \%$. B. Detalles de la morfología de las colonias. Obsérvense colonias pequeñas, grises o blancas, brillantes, convexas, lisas y levantadas. Tomado de Wikimedia Commons, categoría "Bordetella pertussis". Creative Commons Attribution 2.0 Generic license. 


\section{Inmunofluorescencia directa}

La prueba de inmunofluorescencia directa busca la detección directa del antígeno mediante anticuerpos fluorescentes. Este método utiliza anticuerpos (monoclonales o policlonales) específicos conjugados con diversos fluorocromos. Los ensayos de immunofluorescencia directa con sueros policlonales se han utilizado para obtener un diagnóstico presuntivo o para confirmar el resultado del cultivo de Bordetella pertussis. Sin embargo, la reactividad cruzada de estos sueros con otras especies de bacterias u otros antígenos presentes en las muestras han conducido a altas tasas ( $85 \%)$ de resultados falsos negativos, los cuales también dependen en gran medida de la experticia del personal de laboratorio. Una de las consecuencias de estos resultados falsos negativos es el retraso en la instauración del tratamiento (hasta que Bordetella pertussis se aísle en cultivo) lo cual lleva a un incremento de la morbilidad [38].

Una manera para mejorar significativamente la técnica de immunofluorescencia directa ha sido el desarrollo de reactivos altamente específicos y de alta afinidad como los anticuerpos monoclonales, los cuales se han utilizado ampliamente en varios laboratorios. La identificación de un antígeno blanco para un diagnóstico particular es el paso clave para la producción de anticuerpos monoclonales. En este contexto varios anticuerpos monoclonales como el BL-1 a BL-7 se han desarrollado específicamente para reconocer las moléculas de lipopolisacáridos de Bordetella pertussis, los cuales no han mostrado reactividad cruzada con otras bacterias presentes en la región nasofaríngea [39]. No obstante a estos avances, algunos reportes, incluyendo los de los CDC, han mostrado que la prueba sigue presentado bajos porcentajes de sensibilidad (65\%), aun cuando lo especificidad es muy variable, llegando hasta el $99 \%$, por lo que no se recomienda como un método diagnóstico $[19,40]$.

\section{Serología}

La infección con Bordetella pertussis es seguida del incremento en la concentración sérica de los anticuerpos tipo IgA, IgG e IgM contra antígenos específicos. Entre los antígenos bacterianos contra los cuales se generan anticuerpos se encuentran: la toxina pertussis, la hemaglutinina filamentosa, la pertactina, las fimbrias y la toxina adenilato ciclasa. De estos, la toxina pertussis es el antígeno más utilizado para la determinación serológica porque es muy específico para esta especie. Existen diversas metodologías para determinar estos anticuerpos, entre las que se incluye la ELISA, la microaglutinación, la fijación del complemento, la hemaglutinación indirecta, los inmunoblots y la neutralización de la toxina. No obstante, en la actualidad, el método de ELISA es el más utilizado en la práctica clínica por su mejor estandarización [41]. 
En general, las clases de anticuerpos más usados con fines diagnósticos de Bordetella spp son las inmunoglobulinas tipo IgG e IgA. La serología puede resultar especialmente útil posterior a la antibioterapia y cuando el cultivo y la reacción en cadena de la polimerasa (PCR) no se encuentran asequibles o aportan resultados negativos [41].

Hoy en día se recomienda la medición sérica de IgG contra la toxina pertusis (IgGanti-TP) para confirmar el diagnóstico de tosferina, aunque también se puede detectar en saliva, con una sensibilidad del $80 \%$ y una especificidad del $97 \%$. Los títulos de corte se deben encontrar entre $50 \mathrm{UI} / \mathrm{mL}$ y $100 \mathrm{UI} / \mathrm{mL}$, con una sensibilidad del $76 \%$ y una especificidad del $99 \%$. Entre los inconvenientes de medir la IgG se encuentra que no permite distinguir si la respuesta inmune es secundaria a la infección o bien inducida por la vacunación. La determinación de IgA-anti-TP sólo se deberá utilizar cuando se cuente con un resultado de IgG-anti-TP indeterminado o cuando no se pueda obtener una segunda muestra [35].

Según las recomendaciones de los CDC el tiempo óptimo para la toma de muestras para ELISA debe ser entre dos a ocho semanas del inicio de la tos, momento en que los títulos de anticuerpos son más altos; sin embargo, la serología se podría realizar incluso hasta la semana 12 luego del inicio de los síntomas [40].

Por otro lado, el aislamiento de Bordetella pertussis en nuestro medio, la mayoría de las veces, no se realiza en el niño mayor y en aquel en el que el curso de la enfermedad es moderada, ya que resulta poco práctico aislarlos teniendo en cuenta que esto no va a cambiar el curso de la enfermedad; en su lugar se lleva a cabo tratamiento empírico con antimicrobianos [19,32].

\section{Reacción en cadena de la polimerasa}

La reacción en cadena de la polimerasa (PCR) es una prueba de biología molecular para la amplificación de genes blanco específicos de la especie de estudio. En el contexto de la tosferina es útil para el diagnóstico rápido, sensible y específico para detectar la infección por Bordetella pertussis en distintas etapas de la enfermedad, con muy buena utilidad tanto en niños no vacunados como en los vacunados. El uso de la PCR utilizando muestras respiratorias se ha ido generalizando en los últimos años y aún más con la implementación de la PCR en tiempo real. La eficacia de esta prueba depende de una adecuada toma de la muestra y la rapidez en su análisis $[7,35,42]$, por lo que se recomienda la toma de la muestra nasofaríngea con un hisopo de dacrón. Actualmente, la técnica permite detectar Bordetella, bien sea de la especie pertussis o parapertussis, aun en pacientes con antibioterapia, pero la sensibilidad disminuye con el paso de los días. La sensibilidad también es menor en los niños y los adultos que han recibido dosis de vacuna antipertúsica [19]. 
Cuando se utiliza en el laboratorio la PCR como diagnóstico se pueden generar resultados falsos positivos debido a la contaminación o reactividad cruzada. El uso de la PCR en tiempo real ayuda a minimizar el riesgo de falsos positivos porque se realiza en tubos cerrados y no se requiere el manejo posterior del material amplificado (amplicones). Desde hace algunos años se ha adoptado a la PCR en tiempo real como un método de rutina para el diagnóstico de Bordetella pertussis en diversos países europeos y norteamericanos [42].

La literatura reporta una sensibilidad entre el $70 \%$ y el $99 \%$ y una especificidad entre el $86 \%$ y el $100 \%$ de la PCR en tiempo real para Bordetella pertussis. Esta variabilidad depende de las condiciones de realización de la técnica, el formato utilizado y las condiciones de ciclado; sin embargo, el factor más importante es el tipo de blanco genómico utilizado. Se han estudiado diferentes blancos genómicos; los genes más estudiados son los IS481, adenilato ciclasa cyA, porina, pertactina, $B P 283, B P 485, p t x S 1$ (subunidad-1 de la toxina pertussis), entre otros [35].

Múltiples estudios con diferentes técnicas para la detección de Bordella pertussis se han realizado para mejorar la calidad y efectividad a la hora de dar el diagnóstico de la tosferina; entre estos se encuentra el sistema automatizado de PCR múltiples para infecciones respiratorias conocido como FilmArray (BioMérieux, Marcy-I'Étoile, Francia), que detecta múltiples patógenos, incluyendo Bordetella pertussis, y se enfoca directamente en la región promotora del gen de la toxina pertussis. En un estudio realizado en la Universidad de Atlanta, Estados Unidos, se comparó este método diagnóstico con la PCR en tiempo real, encontrando mejores resultados con esta última, ya que se puede utilizar en un centro de atención con mayor facilidad en su uso y con una alta especificidad, partiendo de que los ensayos FilmArray detectan aproximadamente 1:3 casos de Bordetella pertussis en comparación con la PCR en tiempo real [43].

En 2005 el Grupo de Consenso Pertussis recomendó como muestras óptimas para la realización de las PCR en los bebés los aspirados nasofaríngeos y en los niños mayores el frotis de garganta [44]. En diferentes instituciones pediátricas y laboratorios de los Países Bajos se realizó un estudio donde midieron la eficacia de la PCR en tiempo real como procedimiento diagnóstico para detectar Bordetella pertussis, utilizando como técnica de recolección de la muestra hisopados nasofaríngeos y frotis de garganta, incluso en pacientes asintomáticos [36]. Estos métodos de recolección proporcionaron suficiente moco con células columnares epiteliales respiratorias, la célula diana para la infección por Bordetella pertussis, haciendo de esta muestra la más ideal para un diagnóstico rápido, sensible y específico, que puede detectar infecciones tempranas y tardías en la progresión de la enfermedad. Además, este método puede ser usado en niños vacunados y en los que la serología es poco fiable; sin embargo, se debe tener en cuenta que la eficacia depende de la experiencia por parte de la unidad asistencial. 
En un estudio sobre tosferina realizado en Korea se encontró una gran asociación entre los vómitos postusivos y la positividad de la PCR para Bordetella pertussis, que demuestran la gran importancia que tienen los vómitos a la hora de sospechar de la enfermedad en un paciente que consulta al servicio médico con síntomas de tos asociados a vómitos postusivos [45].

\section{Diagnóstico diferencial}

El diagnóstico diferencial de la tosferina es el síndrome coqueluchoide, el cual es una entidad que se relaciona con la enfermedad por su gran similitud tanto clínica como en el laboratorio, con la única diferencia de su etiología y de la progresión de la enfermedad [37]. En el momento en que los signos y síntomas son indistinguibles de la tosferina, pero no es posible demostrar la presencia de Bordetella pertussis o de otro agente, ya sea viral o bacteriano diferente a este, se le atribuirá el diagnóstico de síndrome coqueluchoide $[25,45,46]$.

Entre los microorganismos que pueden causar síndrome coqueluchoide están Mycoplasma pneumoniae, Chlamydia trachomatis, Bordetella bronchiseptica y los virus como el virus sincitial respiratorio (VSR), rinovirus, adenovirus, virus de la influenza y virus de la parainfluenza humana $[25,45]$. La clínica del síndrome coqueluchoide es similar, pero mucho más leve que la del coqueluche y generalmente no suele llegar a tener las complicaciones tan graves a las que la tosferina conlleva $[45,46]$.

El diagnostico de este síndrome se hace de la misma forma que para la tosferina, con cultivo por hisopado nasofaríngeo; la principal diferencia que tienen ambas entidades es el agente etiológico, el cual va a decir que un paciente presenta un síndrome coqueluchoide cuando se aísla cualquier microorganismo diferente a los principales agentes de la tosferina, ya sea virus o bacteria $[25,45,46]$.

\section{Tratamiento}

La hospitalización se considera importante en el lactante menor de tres meses, ya que este paciente presenta las formas más severas de coqueluche como la apnea. Se debe realizar aislamiento con todas las medidas. Es necesario tener en cuenta la aspiración de secreciones ya que pueden afectar el curso de la enfermedad y la aparición de complicaciones [31,32].

El oxígeno a una concentración y humedad adecuadas es primordial para el tratamiento pues ayuda en las crisis de tos prolongada y previene la cianosis [28].

Debido a la relación entre los accesos de tos y la alteración psíquica se ha planteado siempre el uso de sedantes como el fenobarbital, meprobamato, diazepam y la tioridazina, aunque estos no presentan casi respaldo científico [32]. 
Últimamente se ha propuesto para el tratamiento de la tos convulsiva el uso de corticosteroides, debido a que se cree que intervienen en el proceso inflamatorio en el tracto respiratorio producido por el coqueluche y en la posible reacción de los antígenos sobre el centro de la tos. Además, en el comienzo de la fase paroxística puede tener un efecto beneficioso, pero, de acuerdo a estudios realizados posteriores, no se recomienda su uso en los casos severos $[22,32]$.

\section{Tratamiento y profilaxis antimicrobiana recomendada por la Academia Americana de Pediatría}

Los macrólidos como la azitromicina son el pilar del tratamiento y profilaxis en los lactantes menores de seis meses de edad con tosferina. En estos pacientes la elección del tratamiento antimicrobiano requiere especial atención ya que la Administración de Medicamentos y Alimentos (FDA; del inglés, Food and Drug Administration) de Estados Unidos no ha aprobado el uso de la azitromicina y la claritromicina en esta población; no obstante, desde 2006 la Academia Americana de Pediatría (del inglés, American Academy of Pediatrics) recomienda el uso de azitromicina en los lactantes de 0-6 meses por el riesgo de estenosis hipertrófica del píloro asociada al uso de eritromicina, aunque recientemente se han reportado dos casos asociados a azitromicina, y en caso de intolerancia a los macrólidos se indica el uso de clotrimoxazol $[26,47]$.

El tratamiento y profilaxis antimicrobiana, de acuerdo con la Academia Americana de Pediatría, varía de acuerdo a la edad de la siguiente manera [48]:

- En menores de 1 mes: la azitromicina es recomendada a una dosis única de $10 \mathrm{mg} / \mathrm{kg} /$ día durante cinco días. La eritromicina no es de primera elección porque se asocia con estenosis pilórica hipertrófica infantil, aunque se puede usar si no se dispone de azitromicina a una dosis única de 40-50 mg/kg/día divididos en cuatro días. La claritromicina no es recomendada en este grupo de edad, ya que no se dispone de datos de seguridad. El trimetoprim-sulfametoxazol está contraindicado en lactantes menores de dos meses por riesgo de kernícterus.

- En lactantes de 1-5 meses: la azitromicina a una dosis única de $10 \mathrm{mg} / \mathrm{kg} /$ día durante cinco días. La eritromicina a una dosis de $40-50 \mathrm{mg} / \mathrm{kg} /$ día dividido en cuatro dosis durante 14 días. La claritromicina a una dosis de $15 \mathrm{mg} / \mathrm{kg} / \mathrm{día}$ dividido en dos dosis durante siete días. El trimetoprim-sulfametoxazol en lactantes mayores de dos meses a una dosis de trimetoprima de $8 \mathrm{mg} / \mathrm{mg} / \mathrm{kg} / \mathrm{día}$ y de sulfametoxazol de $40 \mathrm{mg} / \mathrm{kg} /$ día divididos en dos dosis durante 14 días.

- En lactantes mayores de 6 meses y niños: la azitromicina a una dosis única durante cinco días de $10 \mathrm{mg} / \mathrm{kg} /$ día el primer día y luego de $5 \mathrm{mg} / \mathrm{kg} /$ día (máximo $500 \mathrm{mg}$ los días dos al cinco). La eritromicina a una dosis de $40-50 \mathrm{mg} / \mathrm{kg} /$ día (máximo $2 \mathrm{~g} /$ día) dividido en cuatro dosis durante 14 días. La claritromicina 
a una dosis de $15 \mathrm{mg} / \mathrm{kg} /$ día en dos dosis (máximo $1 \mathrm{~g} /$ día) durante 7 días. La trimetroprima a $8 \mathrm{mg} / \mathrm{kg} /$ día y el sulfametoxazol a $40 \mathrm{mg} / \mathrm{kg} /$ día divididos en dos dosis durante 14 días.

- En adultos: la azitromicina a una dosis única de $500 \mathrm{mg}$ el primer día y luego de $250 \mathrm{mg} /$ día los días dos al cinco. La eritromicina $2 \mathrm{~g} /$ día dividido en cuatro dosis durante 14 días. La claritromicina $1 \mathrm{~g}$ /día dividido en dos dosis durante 7 días. La trimetroprima a $320 \mathrm{mg} /$ día y el sulfametoxazol a $1.600 \mathrm{mg} /$ día divididos en dos dosis durante 14 días.

- El trimetoprim-sulfametoxazol se usa en pacientes mayores de dos meses alérgicos a los macrólidos o infectados con cepas de Bordetella pertussis resistente a los macrólidos [5,7,17-20,30,45].

- En un hospital regional de Korea, durante un estudio en 57 niños con infección por tosferina, confirmada microbiológicamente en muestras nasales para Bordetella pertussis, se realizó la detección de ADN para este microorganismo usando la amplificación isotérmica mediada por bucle (LAMP; del inglés, loopmediated isothermal amplification). En estos pacientes se midieron las concentraciones inhibitorias mínimas para seis antimicrobianos (eritromicina, claritromicina, azitromicina, minociclina, amoxicilina y trimetoprim-sulfametoxazol) contra 30 cepas aisladas, donde todas las cepas fueron susceptibles a todos los antimicrobianos. Esto permitió concluir que la vacuna contra la tosferina adicional en niños mayores es necesaria, y que la estrategia con estos fármacos antimicrobianos se pueden usar contra la tosferina, siendo más especifica la estrategia con macrólidos [45].

\section{Tratamiento de soporte}

Además del esquema antimicrobiano es importante brindar al paciente tratamiento de soporte, como se describirá a continuación.

\section{Solución hipertónica}

Es una solución concentrada de sal en agua. La concentración más utilizada es de aproximadamente $7 \%$ de sal, el doble de sal que contiene el agua de mar, cuyo rango de concentración puede variar según la necesidad. La principal forma de administración y la más útil es vaporizada mediante un nebulizador que hace que se evapore y llegue directamente a las vías respiratorias y los pulmones [19]. Esta sustancia es inhalada a nivel pulmonar y las células que tapizan la vía aérea se encargan de diluirla. Una vez estas se activan permiten afluir el agua que ayuda a rescatar la humedad de la vía aérea y del mismo modo da paso a que el moco se libere [49].

No se ha encontrado evidencia suficiente para afirmar que la solución hipertónica sea beneficiosa para todos los trastornos respiratorios. Esta solución es útil en en- 
fermedades que son generadas por infecciones y no para aquellas donde se produce un estrechamiento de la vía aérea como en el asma, el enfisema y la enfermedad pulmonar obstructiva crónica (EPOC), en las cuales perpetuaría el daño. Como uno de sus efectos adversos se ha encontrado que la utilización de la solución hipertónica puede provocar el estrechamiento de las vías aéreas, aunque el uso de un broncodilatador previamente puede limitar este efecto de manera eficaz. Otro efecto adverso es la tos que se genera al iniciar las nebulizaciones con la solución hipertónica; no obstante, en la gran mayoría de veces tiende a descender al pasar las primeras dosis; lo que se recomienda es que en los pacientes en los que la tos no disminuye se les administre una concentración menor de sal para que sea mejor tolerada [50].

La solución salina hipertónica al 3\% tiene propiedades benéficas en el tratamiento de la bronquiolitis, que se puede evidenciar en la tosferina, aunque aún no se encuentran resultados sobre estudios al respecto. Entre los efectos positivos se encuentra que impide la conexión iónica en las secreciones mucoides, disminuyendo su viscosidad, elasticidad y densidad; además, incrementa el intercambio osmótico de agua hacia el interior de la cubierta del moco, ayudando a su secreción por medio de la rehidratación de este. Finalmente, mejora el espasmo a nivel respiratorio y fomenta el proceso de la tos, ayudando a generar esputo para así eliminar las secreciones [49].

\section{Profilaxis a los contactos del paciente}

Se ha evidenciado que la enfermedad se puede dar en cerca del $100 \%$ de los contactos susceptibles, por lo tanto, es de suma importancia realizar la profilaxis. La Academia Americana de Pediatría recomienda dar profilaxis al grupo familiar del paciente, sea cual sea su edad y su historial de vacunación. La sugerencia es administrar la profilaxis a los contactos que se encuentren asintomáticos dentro del rango de 21 días de iniciada la tos en el paciente para ayudar a prevenir la transmisión secundaria. En nuestro país la quimioprofilaxis está indicada en los familiares directos o aquellos que conviven con el paciente en la misma vivienda y en los que presentan riesgo de enfermedad grave o complicada como $[6,19]$ :

1. Menores de dos años con vacunación incompleta (menor a tres dosis)

2. Maternas en el último trimestre de embarazo

3. Mayores de 65 años

4. Individuos con comorbilidades asociadas (cardiopulmonares crónicas con capacidad funcional limitada)

5. Hospitalizados en misma sala que el caso, que no cumplan con una distancia de un metro entre las dos camas o cunas 
6. Trabajadores de la salud y profesorado escolar expuesto al riesgo, sólo en caso de brotes

\section{Tratamiento para el paciente con coqueluche grave}

Todo paciente menor de tres meses de edad y con sospecha de coqueluche debe ser evaluado de manera hospitalaria si se evidencia la presencia de Bordetella pertussis en su nasofaringe, durante cinco a siete días hasta descartar complicaciones. El paciente con diagnóstico confirmado o no debe ser observado de manera directa en una unidad de cuidados intensivos. El tratamiento pilar es conservar unos niveles adecuados de oxígeno $\left(\mathrm{O}_{2}\right)$ en sangre y que la hemodinámia esté estable $[19,20]$.

\section{Hemodinámia}

La adecuada perfusión con líquidos está a la cabeza del tratamiento para evitar la baja perfusión debido al shock, que es de muy mal pronóstico pues perpetúa el daño hemodinámico que se da por el aumento de la acidosis y la hipoxemia. Los medicamentos vasoactivos de preferencia son las catecolaminas con efecto inotrópico como la dobutamina o la epinefrina como los inhibidores de la fosfodiesterasa III, siendo la milrinona la opción a elegir $[19,20]$.

\section{Ventilación mecánica}

Debido a la gravedad del shock cardiogénico la instauración de la ventilación mecánica debe ser realizada prontamente. Es de suma importancia tener presente que si el paciente presenta hipertensión pulmonar la hiperventilación debe ser de manera moderada, tratando de mantener la presión de $\mathrm{CO}_{2}$ entre $30-35 \mathrm{mmHg}$, ya que valores inferiores perpetuán el daño [20].

\section{Vasodilatores pulmonares}

El sildenafilo es un inhibidor de la fosfodiesterasa $V$ que bloquea el funcionamiento del guanosín monofosfato cíclico (GMPc), produciendo un efecto vasodilatador, y es de utilidad en sinnúmero de condiciones patológicas. En la actualidad, la dosis recomendada de sildenafilo no está decidida en la población infantil, pero es posible que esté entre $0,3 \mathrm{mg} / \mathrm{kg}$ y $1 \mathrm{mg} / \mathrm{kg}$, tres veces al día [20].

\section{Soporte vital extracorpóreo}

Diferente de lo evidenciado en la hipertensión pulmonar persistente en el neonato, los resultados arrojados con el soporte vital extracorpóreo (ECMO; del inglés, Extra Corporeal Membrane Oxygenation) en el coqueluche grave han sido poco alentadores, mostrando un valor de sobrevida del $40 \%$, un porcentaje menor respecto a la mortalidad de aquellos pacientes que fueron internados a ECMO por otras patologías, que sugiere que se debe estudiar más sobre el tema [5]. 


\section{Terapias de leucorreducción}

La exanguinotransfusión se ha planteado como un proceso dirigido a disminuir la cantidad de leucocitos circulantes, que como resultado genera un efecto mecánico en la vasculatura pulmonar. Este procedimiento es una alternativa terapéutica en el escenario de una hiperleucocitosis, definida como una cifra de leucocitos superior a $100.000 / \mu \mathrm{L}$, ya que representa un factor de riesgo mortal en los casos de coqueluche grave, debido a su asociación con el síndrome de hiperviscosidad que genera la aparición de trombos leucocitoclásticos, que producen una obstrucción mecánica en la zona vascular pulmonar [5].

Existen estudios que han descrito una serie de casos exitosos en pacientes menores de seis meses de edad sometidos a exanguinotransfusión, en los que se observó una mejoría a nivel de la oxigenación después de realizado el procedimiento y un descenso importante en los signos indirectos de hipertensión pulmonar [5]. Es de importancia clínica conocer que los pacientes luego de la exanguinotransfusión tienden a presentar un efecto rebote en los valores del recuento leucocitario, que es lo que indicará si se repite o no el procedimiento. Además, el efecto que quizás pueda tener sobre los niveles de toxemia por la toxina pertussis aún no ha sido analizado [19].

\section{Vacunación}

En Colombia la guía del Ministerio de Salud y la Protección Social estipula el siguiente esquema de vacunación que incluye inmunidad contra tosferina [6]:

- A los dos meses de edad: se aplica la vacuna pentavalente DPT-HB+Hib, a una dosis, por vía intramuscular, compuesta por antígenos de la difteria, el tétano, la tosferina, Haemophilus influenzae tipo b y la hepatitis B.

- A los cuatro meses de edad: se aplica la vacuna pentavalente, a dos dosis, por vía intramuscular, cuyos componentes son antígenos de la difteria, el tétano, la tosferina, Haemophilus influenzae tipo b y la hepatitis $\mathrm{B}$.

- A los seis meses de edad: se aplica la vacuna pentavalente, a tres dosis, por vía intramuscular, la cual está compuesta por antígenos de la difteria, el tétano, la tosferina, Haemophilus influenzae tipo b y la hepatitis B.

- Al año de la tercera dosis (18 meses de edad): se aplica el primer refuerzo de la vacuna DPT, que contiene antígenos de la difteria, el tétano y la tosferina, por vía intramuscular.

- A los cinco años de edad: se aplica el segundo refuerzo de la vacuna DPT, que contiene antígenos de la difteria, el tétano y la tosferina, por vía intramuscular. 
La vacunación constituye la principal herramienta para la prevención de la tosferina y una alta cobertura de vacunación de rutina es fundamental en la lucha contra esta enfermedad. Aunque el hecho de tener la vacuna no exonera al individuo de presentar la enfermedad, debido a que las tres dosis de la vacuna inducen sólo títulos de anticuerpos contra la tosferina entre el $70 \%$ y el $85 \%$. Esta inmunidad presenta una caída sensible entre los cuatro y los siete años después de la vacunación, por ello, se deben aplicar dos dosis de refuerzo, una a los 18 meses y otra a los cinco años de edad [39]. En Estados Unidos se recomienda promover la inmunidad al tétano, la difteria y la tosferina a través del uso de la vacuna DPT5 (Adacel ${ }^{\circledR}$ ), de forma rutinaria entre los 11 y 12 años de edad [1,21,22] [47,51-53].

Los grandes problemas de la tosferina en nuestro país es el impacto que recae en la mayoría de los casos sobre los lactantes menores de seis meses, en quienes la enfermedad es más grave. Por tal razón, se propone una nueva medida de vacunación que ya se está implementando en otros países como Estados Unidos y Argentina y que consiste en una dosis de la vacuna triple viral en las mujeres embarazadas, a la semana 20 de gestación, ya que esto disminuye la incidencia y el riesgo en los menores de seis meses de edad de padecer la enfermedad [54].

La vacuna acelular (DPTa), introducida en Colombia en 2006, es una muy buena herramienta en la prevención de la enfermedad. Esta estrategia tiene un gran impacto en los lactantes, los cuales son afectados por la severidad de la enfermedad y con más morbimortalidad en el territorio colombiano. En el 2012, el Comité Asesor sobre Prácticas de Inmunización (ACIP; del inglés, Advisory Committee on Immunization Practices) de los CDC de los Estados Unidos recomendó que las mujeres gestantes se vacunen con la DPTa durante cada embarazo, independiente de su historia de inmunización, de modo que se convierta en un tipo de método profiláctico para la madre y para él bebé, ya que los anticuerpos la protegen a ella y se transfieren de forma pasiva al feto [39]. Sin embargo, la administración de la vacuna posparto no está recomendada ya que sólo le provee una inmunidad a la madre, poniendo en riesgo al lactante de adquirir la enfermedad; sin contar que si la madre se aplica la vacuna únicamente presentará los niveles adecuados de anticuerpos a las dos semanas, colocando también en riesgo los demás miembros de su hogar [1].

Este nuevo método de vacunación contra la tosferina previene de manera eficaz las hospitalizaciones infantiles y las muertes por la enfermedad, y es un buen método que se debe ayudar a que se implemente más, se le dé mayor cubrimiento, se promuevan esfuerzos en los prestadores de servicios de salud y se eduque a las maternas y a la sociedad en general para proteger tanto a la madre como al bebé de la tosferina. Esta recomendación es apoyada por el Colegio Americano de Obstetras y Ginecólogos (ACOG; del inglés, American College of Obstetricians and Gynecologists) y el Colegio Americano de Enfermeras Parteras (ACNM; del inglés, American College of Nurse-Midwives) [54-56]. 
En la actualidad no se dispone en el medio de una vacuna que brinde una inmunidad duradera, por lo tanto, las dosis de refuerzo son una muy buena opción y una estrategia que se debería implementar para reducir los índices de tosferina en las poblaciones de adolescente y adultos, en los cuales ya se ha perdido la inmunidad que se dio con el esquema habitual de la niñez [8]. Se han realizado estudios, por ejemplo, en Suecia que han demostrado la eficacia y la seguridad en crear una respuesta inmunológica mediada por células $B$, con su consecuente producción de anticuerpos, en adolescentes entre los 14 y los 16 años vacunados con la vacuna triple viral acelular. Esta medida se empezará a implementar a partir de 2016 en este país [55].

Como se ha resaltado a lo largo de este documento los contactos familiares tienen un papel importante en la transmisión de la tosferina y, según estudios, se ha demostrado que los niños de uno a tres años después de la vacunación son más susceptibles a la tosferina. También se ha logrado demostrar que se puede producir la enfermedad después de la vacunación y no siempre con los síntomas típicos de la infección, pues la vacuna, al disminuir la gravedad de la enfermedad, conduce a que la presentación de la tosferina sea más silenciosa, a diferencia de los niños que no son vacunados, en quienes la enfermedad se da de forma más agresiva, en especial a edades más avanzadas [37].

A través del tiempo se han postulado varias hipótesis sobre el resurgimiento de la tosferina. Como se mencionó anteriormente, otra de las posibles causas es la aparición de cepas que albergan alelos diferentes de los antígenos de la cepa de la vacuna para la tosferina [19]. Desde el 2005, la FDA aprobó dos vacunas acelulares: Adace ${ }^{\circledR}$, aplicable desde los 11 a los 64 años, y Boostrix ${ }^{\circledR}$, aplicable entre los 10 y los 18 años. Los componentes antigénicos de ambas vacunas se encuentran en dosis más bajas que en las vacunas acelulares que se usan en los niños menores de siete años. Todos los estudios han evidenciado una adecuada inmunogenicidad, un perfil de seguridad apropiado, así como una buena eficacia $[19,54]$.

Adacel ${ }^{\circledR}$ y Boostrix ${ }^{\circledR}$ están comercialmente disponibles y se puede usar cualquiera de las dos, especialmente en adolescentes después de los 10 años de haber recibido la vacuna del programa nacional de inmunización en $2^{\circ}$ año básico (dT), agregando refuerzos cada 10 años, para así sostener una adecuada inmunidad contra el tétano, la difteria y el coqueluche [52]. Finalmente, la primera opción consiste en la administración de la vacuna Tdap a las mujeres que acaban de dar a luz antes del alta del hospital $[18,55]$.

\section{Conclusiones}

En general, los hallazgos y avances en el estudio de la tosferina, derivados de la presente revisión, evidencian que es una entidad clínica con un aumento signi- 
ficativo en su incidencia en la población pediátrica. A pesar de que se cree que está totalmente controlada, es una enfermedad que ha venido presentando brotes de alta relevancia. Debido a que la enfermedad se mantiene en un bajo perfil su diagnóstico puede pasar desapercibido en muchas ocasiones, por ello, es fundamental comenzar a tener presente la tosferina como diagnóstico diferencial en los pacientes pediátricos (desde la etapa de neonatos hasta la adolescencia) con tos crónica por más de 15 días, especialmente en aquellos en que se acompaña de otros síntomas como emesis y estridor.

Una vez que se sospeche el síndrome de coqueluche, con ayuda de los criterios clínicos, se debe seguir con su confirmación por medio del sesgo epidemiológico y las pruebas de laboratorio, en las que se demostrará el principal agente etiológico, Bordetella pertussis, y se excluirá su principal diagnóstico diferencial, el síndrome coqueluchoide. El tratamiento de la tosferina está enfocado en resolver los síntomas y en erradicar definitivamente el agente etiológico, por medio de la implementación de macrólidos como piedra angular y la utilización de agentes antitusivos, antieméticos y oxígeno, entre otras medidas.

La principal preocupación se centra en los lactantes menores, población mayormente afectada por Bordetella pertussis, la cual puede ocasionar un desarrollo fatal en el paciente pediátrico. Esta es una de las razones por las que se ha venido trabajando en el mejoramiento de la vacuna en relación con su efectividad, tiempo de protección y menores factores adversos. Así mismo, se resalta la importancia de estrategias para realizar los refuerzos en la población juvenil y adulta, teniendo en cuenta que los niveles de protección inmune disminuyen considerablemente en estas etapas de la vida, convirtiéndose en la población de reservorio asintomático de la enfermedad, con un alto impacto de transmisión a la población más susceptible, que es la población infantil donde la enfermedad es potencialmente fatal.

\section{Agradecimientos}

Queremos dar un agradecimiento muy especial a la doctora Isaura Pilar por haber sido la guía y soporte como asesora metodológica, pues gracias a su constancia y disciplina se pudo concluir satisfactoriamente este manuscrito.

\section{Bibliografía}

1. Andrade S. La vacuna contra la tos ferina es eficaz, pero la inmunidad tiende a debilitarse con el tiempo. Minnesota, Estados Unidos: Mayo Clinic. 2016. Disponible: http:// newsnetwork. mayoclinic.org/discussion/lavacuna-contra-la-tos-ferina-es-eficaz-perola-inmunidad-tiende-a-debilitarse-con-el- tiempo/. Consultado: abr 2016.

2. Taffarel $\mathbf{P}$, Bonetto G, Haimovich A. Coqueluche grave, evolución y exanguinotransfusión como tratamiento alternativo: Serie de casos. Arch Argent Pediatr 2012; 110: 327330. 
3. Grupo de expertos en vacunación contra tos ferina. Consenso para el diagnóstico clínico y microbiológico y la prevención de la infección por Bordetella pertussis. Salud Pública Méx 2011; 53: 57-65.

4. Montilla Velásquez MdP, Camacho Moreno G, Romero SL, Gómez K. Factores de riesgo asociados a complicaciones por Bordetella pertussis en la Fundación Hospital de la Misericordia, 2009-2013. Infectio 2015; 19: 101-108.

5. Paksu MS, Akgun M, Karadag A, Asilioglu N, Belet N, Sensoy G. Fulminant pertussis in very young infants: two cases and review of the literature. Turk J Pediatr 2013; 55: 426-429.

6. Organización Internacional para las Migraciones, República de Colombia, Ministerio de Salud y Protección Social, Sistema General de Seguridad Social en Salud, Instituto de Evaluación Tecnológica en Salud. Guía de práctica clínica para la identificación y el manejo clínico de la tos ferina en menores de 18 años de edad: Actualización 2014. Bogotá, Colombia. 2014. Disponible: http://gpc.minsalud.gov.co/gpc sites/Repositorio/Otros_conv/GPC_tos_ferina/GPC_Tos_ferina_Completa.pdf. Consultado: abr 2016 .

7. Correa JA, Gómez JF, Posada R. Fundamentos de Pediatría Tomo III. Infectología y Neumología (ed 4a). Medellín, Colombia: CIB; 2013.

8. González Morán F, Moreno Civantos A, Amela Heras C, Pachón del Amo I, García del Busto A, Herrero Carot C, et al. Estudio de un brote epidémico de tos ferina en Castellón. Rev Esp Salud Publica 2002; 76: 311-319.

9. Perret C, Viviani T, Pena A, Abarca $\mathbf{K}_{\text {, }}$ Ferres $\mathbf{M}$. [Source of infection in young infants hospitalized with Bordetella pertussis]. Rev Med Chil 2011; 139: 448-454.

10. Centros para el Control y la Prevención de Enfermedades (CDC). ¿Qué pasaría si suspendiéramos las campañas de vacunación? 2011. Disponible: http://www.cdc.gov/ spanish/inmunizacion/importancia.html\#tos. Consultado: abr 2016.

11. Pérez Cárdenas JE. Los indicios de reemergencia de la tos ferina en colombia, requieren de medidas de prevención más efectivas. Biosalud 2012; 11: 5-6.

12. Niño-Ruiz C, Morón-Duarte L, ÁlvarezLarrañaga MI. Efectividad a corto plazo de la vacuna antipertusis en adolescentes: revisión sistemática. Infectio 2015; 19: 115-123.

13. Hernández Porras M. Tos ferina una enfermedad reemergente. Rev Enfer Infec Pediatr $2011 ; 25$ : 33-34.
14. World Health Organization. The global burden of disease: 2004 Update. Ginebra, Suiza: WHO Press; 2008.

15. World Health Organization. Immunization, Vaccines and Biologicals: Pertussis. 2011. Disponible: http://www.who.int/immunization/topics/pertussis/en/. Consultado: abr 2016.

16. Gentile A, Romanin VS, Juarez Mdel V, Lucion MF, Marques Mde $L$, Mistchenko AS. Epidemiology of Bordetella pertussis in a children's hospital. Arch Argent Pediatr 2014; 112: 26-32.

17. República de Colombia, Ministerio de Salud y Protección Social, Instituto $\mathrm{Na}$ cional de Salud. Protocolo de Vigilancia en Salud Pública: TOSFERINA. Bogotá, Colombia. 2014. Disponible: http://www.ins.gov. co/lineas-de-accion/Subdireccion-Vigilancia/ sivigila/Protocolos $\% 20$ SIVIGILA/PRO $\% 20$ Tos\%20ferina.pdf. Consultado: abr 2016.

18. Pimentel AM, Baptista PN, Ximenes RA, Rodrigues LC, Magalhaes V, Silva AR, et al. Pertussis may be the cause of prolonged cough in adolescents and adults in the interepidemic period. Braz J Infect Dis 2015; 19: 43-46.

19. Moreno-Pérez D, Baquero-Artigao F, Gonzalo-deLiria CR, Cilleruelo-Ortega MJ. Tos ferina. In: Asociación Española de Pediatría ed. Protocolos Diagnóstico-Terapéuticos de la AEP: Infectología pediátrica (ed 3a). Madrid, España: ERGON; 2011: 95-102.

20. Banfi A. Coqueluche: tratamiento y complicaciones. Rev Chil Pediatr 1975; 46: 287290.

21. Donoso A, Arriagada D, Cruces P, Díaz F. Coqueluche grave: Estado del arte. Rev Chil Infectol 2012; 29: 290-306.

22. Quian J, Cerisola A, Russomano F, Fernández $A$, Cappeta $M$, Uriarte $R$, et al. Infecciones por Bordetella pertussis en niños menores de un año hospitalizados y sus contactos del hogar. Arch Pediatr Urug 2006; 77: 229-236.

23. Manzanares S, Lafuente S, Martí M, Simon P, Gorrindo P, Caylà JA. Evolución de la incidencia de tos ferina en la ciudad de Barcelona entre 1999 y 2011. Enferm Infecc Microbiol Clin 2013; 31: 156-158.

24. Dotres Martínez C, Vega Mendoza D, Toraño Peraza G, Álvarez Carmenate M, Broche Morera A. Síndrome coqueluchoide y tos ferina. Rev Cubana Med Gen Integr 2012; 28: 725-734.

25. Molina López J. Tosferina. México D.F., México: Universidad Nacional Autónoma de México (UNAM). 2015. Disponible: http://www. 
facmed.unam.mx/deptos/microbiologia/bacteriologia/tosferina.html. Consultado: abr 2016.

26. Martínez H, Escobar-de la Hoz G. Sección 50: Tosferina. Resúmenes pediátricos (ed 7a). Medellín, Colombia: Coimpresos; 2012: 310-315.

27. Centros para el Control y la Prevención de Enfermedades (CDC). Acerca de la tosferina. Giorgia, Estados Unidos. 2016. Disponible: http://www.cdc.gov/pertussis/about/ index-sp.html. Consultado: abr 2016.

28. Albán ÁM, Arcos FE, Barrios FA, VásquezJiménez JM, Mesa JA. Tos ferina neonatal, una enfermedad emergente. Infectio 2012; 16: $183-186$.

29. Arellano-Penagos M, Aranda-Patrón E, López-Sotomayor LL. Tos ferina diagnosticada clínica y bacteriológicamente en seis casos. Acta Pediatr Mex 2013; 34: 127-131.

30. Buelvas Meza David José. Muerte por tos ferina en un brote ocurrido en el municipio de Caimito (Sucre), perspectiva clínica-epidemiológica. Rev Eviden 2013; 3: 16-22.

31. Han WG, van Twillert I, Poelen MC, Helm $K$, van de Kassteele J, Verheij TJ, et al. Loss of multi-epitope specificity in memory $\mathrm{CD} 4(+) \mathrm{T}$ cell responses to $\mathrm{B}$. pertussis with age. PLoS One 2013; 8: e83583.

32. Villegas D, Echandia-Villegas CA, Echandia CA. Afebrile pneumonia (whooping cough) syndrome in infants at Hospital Universitario del Valle, Cali, 2001-2007. Colomb Med (Cali) 2012; 43: 114-118.

33. Villalobos Pinto E, Martínez-Villanueva J, Cano Fernández J, Flores Pérez P, Sánchez Bayle M. Factores de riesgo de complicaciones y duración del ingreso hospitalario en pacientes con tos ferina. Rev Pediatr Aten Primaria 2012; 14: 207-215.

34. Olivares Ortiz J, Bueno Campaña M. Tos ferina: revisión clínica a propósito de un caso. Rev Pediatr Aten Primaria 2011; XIII: 575584.

35. Aquino Andrade A, Martínez Leyva G, de Colsa Ranero A. Aspectos genómicos de Bordetella pertussis y el camino hacia el nuevo estándar de oro en el diagnóstico de tos ferina. Rev Enfer Infec Pediatr 2011; 24: 139-146.

36. van den Brink G, Wishaupt JO, Douma JC, Hartwig NG, Versteegh FG. Bordetella pertussis: an underreported pathogen in pediatric respiratory infections, a prospective cohort study. BMC Infect Dis 2014; 14: 526.

37. Cano-Rangel MA, Durazo-Arvizu MdLÁ, Dorame-Castillo $\mathbf{R}$, Gómez-Rivera $\mathbf{N}$. Abordaje Diagnóstico del Síndrome Coquelu- choide y Tosferina. Bol Clin Hosp Infant Edo Son 2012; 29: 85-87.

38. Martin D, McNicol P, Marchand R, Lebel P, Peppler MS, Brodeur BR. An improved immunofluorescent reagent for rapid, direct detection of Bordetella pertussis. Can J Infect Dis 1995; 6: 16-18.

39. Archambault D, Rondeau P, Martin D, Brodeu BR. Characterization and comparative bactericidal activity of monoclonal antibodies to Bordetella pertussis lipo-oligosaccharide A. J Gen Microbiol 1991; 137: 905-911.

40. Murphy T, Bisgard K, Sanden G. Chapter 2 - Diagnosis and Laboratory Methods. Atlanta, Estados Unidos: Centers for Disease Control and Prevention. 2000. Disponible: http:// www.cdc.gov/pertussis/outbreaks/guide/ downloads/chapter-02-amended.pdf. Consultado: abr 2016

41. Guiso N, Berbers G, Fry NK, He Q, Riffelmann $\mathbf{M}$, Wirsing von Konig $\mathbf{C H}$. What to do and what not to do in serological diagnosis of pertussis: recommendations from EU reference laboratories. Eur J Clin Microbiol Infect Dis 2011 ; 30: 307-312.

42. Farrell DJ, McKeon M, Daggard G, Loeffelholz MJ, Thompson CJ, Mukkur TK. Rapid-cycle PCR method to detect Bordetella pertussis that fulfills all consensus recommendations for use of PCR in diagnosis of pertussis. J Clin Microbiol 2000; 38: 4499-4502.

43. Jerris RC, Williams SR, MacDonald HJ, Ingebrigtsen DR, Westblade LF, Rogers BB. Testing implications of varying targets for Bordetella pertussis: comparison of the FilmArray Respiratory Panel and the Focus B. pertussis PCR assay. J Clin Pathol 2015; 68: 394-396.

44. Riffelmann $\mathbf{M}$, Wirsing von Konig $\mathbf{C H}$, Caro V, Guiso N. Nucleic Acid amplification tests for diagnosis of Bordetella infections. J Clin Microbiol 2005; 43: 4925-4929.

45. Park S, Lee SH, Seo KH, Shin KC, Park YB, Lee MG, et al. Epidemiological aspects of pertussis among adults and adolescents in a Korean outpatient setting: a multicenter, PCR-based study. J Korean Med Sci 2014; 29: 1232-1239.

46. Gómez-Rivera N, García-Zarate MG, Álvarez-Hernández G, Villalobos-García $L_{\text {, }}$ Fonseca-Chon I, Cano-Rangel MA, et al. Tos Ferina y Síndrome Coqueluchoide en Niños Menores de 1 Año de Edad: Factores de Riesgo Asociada a Mortalidad. Estudio Transversal Descriptivo de 48 Casos. Bol Clin Hosp Infant Edo Son 2011; 28: 2-6.

47. Centers for Disease Control and Prevention. Recommended Antimicrobial Agents for 
Treatment and Postexposure Prophylaxis of Pertussis. MMWR 2005; 54: 1-20.

48. American Academy of Pediatrics. Pertus sis (Whooping Cough). In: Pickering LK, Baker CJ, Kimberlin DW, Long SS eds. Red Book: 2009 Report of the Committee on Infectious Diseases (ed 28a). Illinois, Estados Unidos: American Academy of Pediatrics; 2009: 504519.

49. Martín Martín R, Yep Chullen G, Sánchez Bayle M, Villalobos Pinto E, Flores Pérez P. Estudio sobre la eficacia y utilidad de la solución salina hipertónica al $3 \%$ en la bronquiolitis aguda del lactante hospitalizado. Rev Pediatr Aten Primaria 2013; 15: 109-115.

50. Wood N, McIntyre P, Marshall H, Roberton D. Acellular pertussis vaccine at birth and one month induces antibody responses by two months of age. Pediatr Infect Dis J 2010; 29: 209-215.

51. Centers for Disease Control and Prevention. Pregnancy and Whooping Cough: Vaccinating Pregnant Patients. Giorgia, Estados Unidos. 2015. Disponible: http://www.cdc. gov/pertussis/pregnant/hcp/pregnant-patients.html. Consultado: abr 2016.

52. Marshall GS, Pool V, Greenberg DP, Johnson DR, Sheng $\mathbf{X}$, Decker MD. Safety and immunogenicity of tetanus-diphtheria-acellular pertussis vaccine administered to children
10 or 11 years of age. Clin Vaccine Immunol 2014; 21: 1560-1564.

53. Tomovici A, Barreto L, Zickler P, Meekison W, Noya F, Voloshen $T$, et al. Humora immunity 10 years after booster immunization with an adolescent and adult formulation combined tetanus, diphtheria, and 5-component acellular pertussis vaccine. Vaccine 2012; 30: 2647-2653.

54. Centers for Disease Control and Prevention. Letter to Providers: Tdap and Influenza Vaccination of Pregnant Women. Giorgia, Estados Unidos. 2014. Disponible: http://www. cdc.gov/flu/pdf/professionals/providersletter-pregnant-2014.pdf. Consultado: abr 2016.

55. Andrade BG, Marin MF, Cambuy DD, Fonseca EL, Souza NF, Vicente AC. Complete genome sequence of a clinical Bordetella pertussis isolate from Brazil. Mem Inst Oswaldo Cruz 2014; 109: 972-974

56. Beltrán S. Situación Actual Pertussis o Tosferina en Colombia. Comité Asesor Consultivo en inmunizaciones de Organización Sanitas Internacional (CCIOSI), Comité Vacunas e Infecciones Pediátricas (Asociación Colombiana de Infectologia -ACIN). 2012. Disponible: http://www.acin.org/acin/new/Portals/0/ Alerta_Pertussis_Colombia.pdf. Consultado: abr 2016 .

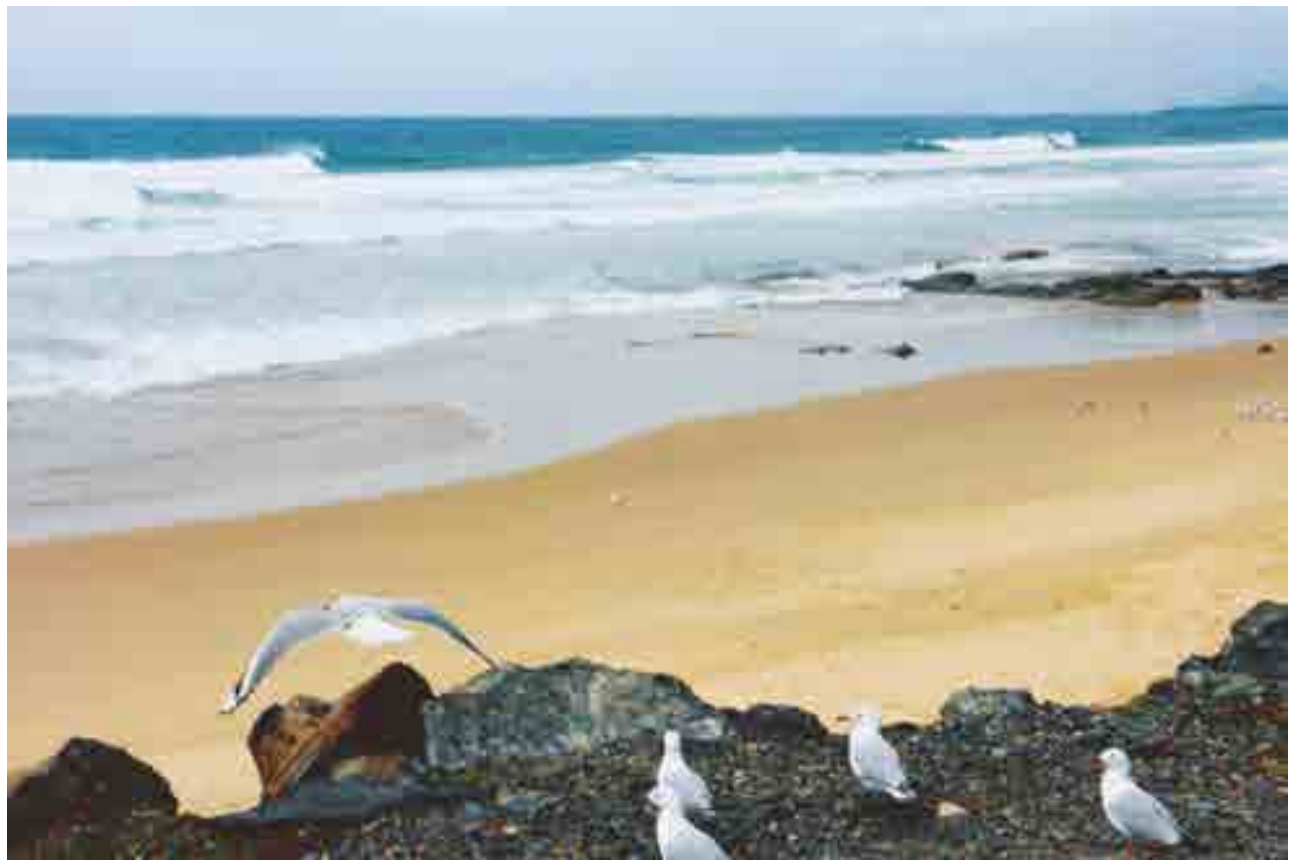

Coff harbour, Australia

Carlos Alberto Lozano M. carloslozano@iatm.com.co 